\title{
Identification of Mycobacterium tuberculosis signal seiquences that direct the export of a leaderless $\beta$-lactamase gene product in Escherichia coli
}

\author{
Anthony J. Chubb, Zenda L. Woodman, \\ Fernanda M. P. R. da Silva Tatley, Hans Jürgen Hoffmann, \\ Renate R. Scholle and Mario R. W. Ehlers
}

Department of Medical Biochemistry, University of Cape Town Medical School, Observatory 7925, South Africa
Author for correspondence: Mario R. W. Ehlers. Tel: +2721406633 5. Fax: + 2721477669 . e-mail:mehlers@physio.uct.ac.za

Proteins secreted by Mycobacterium tuberculosis may play a key role in virulence and may also constitute antigens that elicit the host immune response. However, the $M$. tuberculosis protein export machinery has not been characterized. A library of $\boldsymbol{M}$. tuberculosis H37Rv genomic DNA fragments ligated into a signal sequence selection vector that contained a leaderless $\beta$-lactamase gene and an upstream Tac promoter was constructed. Transformation of Escherichia coli with the $M$. tuberculosis DNA library and selection on plates containing 50-100 $\mu \mathrm{g}$ ampicillin $\mathrm{ml}^{-1}$ resulted in the identification of $15 \mathrm{Amp}$ ' clones out of a total of 14000 transformants. Twelve of the $\beta$-lactamase gene fusions conferred high levels of Ampr (up to $1 \mathrm{mg}$ ampicillin $\mathrm{m}^{-1}$ ); insert sizes ranged from 350 to $3000 \mathrm{bp}$. Of ten inserts that were completely sequenced, two were identified as fragments of the genes for $M$. tuberculosis antigens $85 \mathrm{~A}$ and $85 \mathrm{C}$, which are the major secreted proteins of this pathogen. Seven of the remaining inserts were $\geqslant 97 \%$ identical to hypothetical ORFs in the $M$. tuberculosis genome, one of which encoded a protein with $35 \%$ identity to a low-affinity penicillin-binding protein (PBP) from Streptomyces clavuligerus. Four of the seven hypothetical ORFs encoded putative exported proteins with one or more membrane interaction elements, including lipoprotein attachment sites and type I and II transmembrane (TM) segments. All of the inserts encoded typical signal sequences, with the exception of a possible type II membrane protein. It is concluded that expression of $\beta$-lactamase gene fusions in $E$. coli provides a useful system for the identification and analysis of $\boldsymbol{M}$. tuberculosis signal-sequence-encoding genes.

Keywords: tuberculosis, Mycobacterium, signal sequences, $\beta$-lactamase, export

\section{INTRODUCTION}

Mycobacterium tuberculosis is an aggressive intracellular pathogen that preferentially invades mononuclear phagocytes and establishes persistent intracellular infec-

\footnotetext{
Abbreviations: MCS, multiple cloning site; PBP, penicillin-binding protein; TM, transmembrane.

The GenBank accession numbers for the sequences reported in this paper are AF017098 (plasmid pGB14T-P), AF017099 (pGB14T-V), AF017100 (pGB14T-X), AF017101 (pGB14T-O2), AF017102 (pGB14T-B) and AF017103 (pGB14T-O1).
}

tions that are difficult to eradicate (Fenton \& Vermeulen, 1996). There is evidence that these events are accompanied by the active secretion of proteins and other molecules by the pathogen. Comparative analyses by two-dimensional electrophoresis of proteins produced by intracellular versus broth-grown bacteria have revealed distinct differences, with intracellular bacteria producing proteins not evident during in vitro growth, some of these proteins being secreted (Lee \& Horwitz, 1995). In addition to these specialized proteins, $M$. tuberculosis sheds a large array of proteins regardless of growth conditions, as revealed by extensive analyses of 

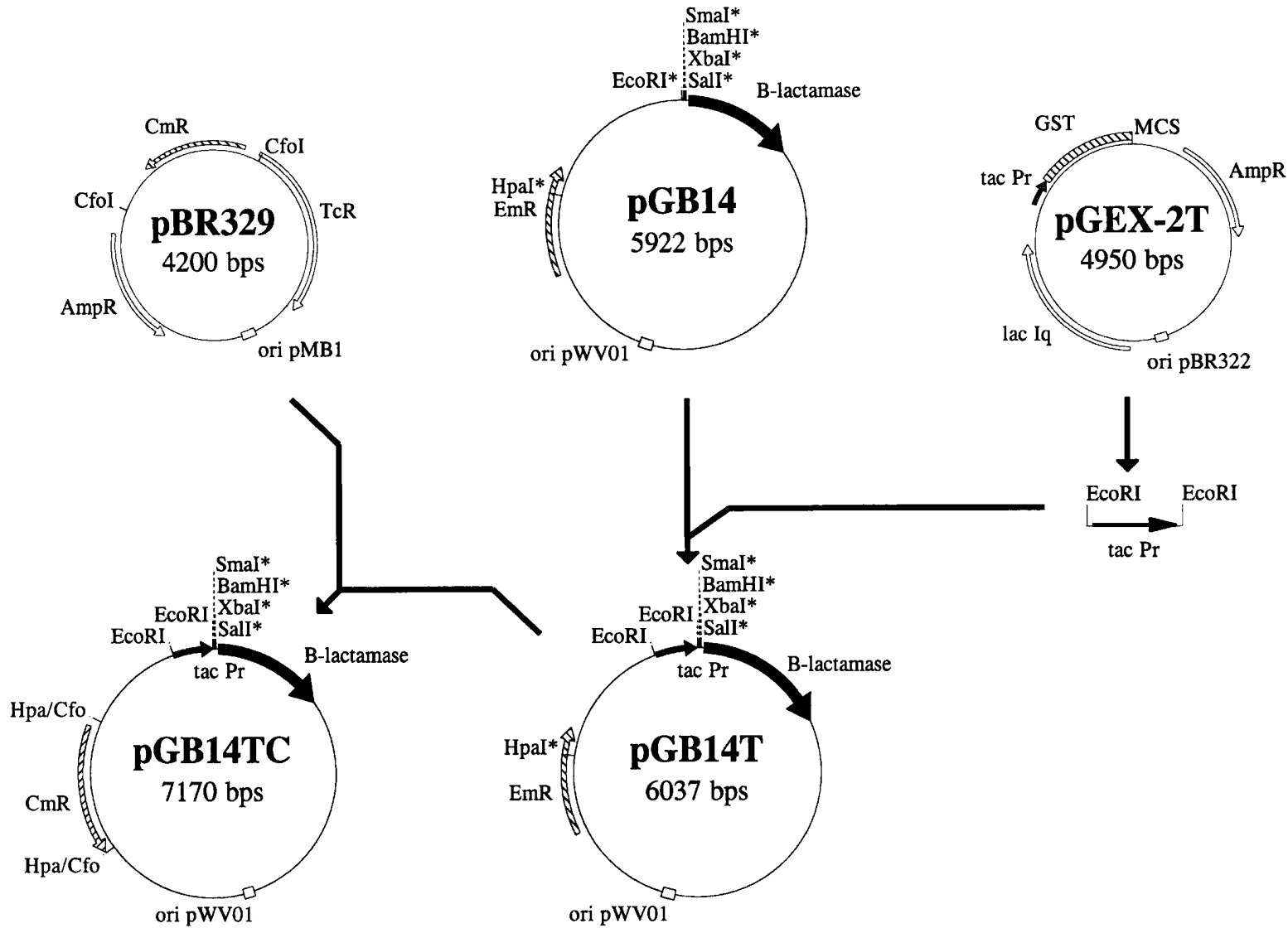

Fig. 1. Construction of plasmids pGB14T and pGB14TC. A PCR-amplified Tac promoter, using pGEX-2T as template, was ligated into the ECORI site in the MCS of pGB14, producing pGB14T. A Cfol-digested fragment of pBR329, containing the $\mathrm{Cm}^{r}$ gene, was ligated into an Hpal site located in the $\mathrm{Em}^{r}$ gene of pGB14T to generate pGB14TC. In both pGB14T and pGB14TC, note the presence of a leaderless $\beta$-lactamase gene, an upstream Tac promoter and an interposed MCS. Asterisks indicate unique restriction sites.

culture filtrates (Andersen, 1994; Sonnenberg \& Belisle, 1997). Many of these are true secreted proteins (Wiker $e t$ al., 1991) and are antigenic in vivo (Orme et al., 1993), and some may prove of value in the design of subunit vaccines (Andersen, 1994; Horwitz et al., 1995). However, at least two issues regarding secreted $M$. tuberculosis proteins remain unresolved. First, what roles, if any, do secreted proteins play in pathogenesis, particularly as virulence factors in cell invasion and intracellular survival? Second, what is the nature of the protein export machinery responsible for the secretion of these proteins?

Three types of protein export pathway have been identified in eubacteria. The best studied is the classical, sec-dependent, general secretory pathway that exports proteins with characteristic $\mathrm{N}$-terminal signal peptides and that is probably the major protein export pathway in both Gram-negative and Gram-positive bacteria (Pugsley, 1993; Salmond \& Reeves, 1993). This pathway is also referred to as the type II secretion system. In addition, subsets of secreted proteins are exported by type I and type III secretion systems, which are sec- and signal-sequence-independent (Salmond \& Reeves, 1993).
The type III system is of particular interest because of its involvement in the export of virulence-associated proteins in diverse bacterial pathogens (Salmond \& Reeves, 1993; Dreyfus et al., 1993; Silhavy, 1997). To date, none of these pathways has been characterized in mycobacteria.

The classical sec-dependent (type II) pathway is presumed to exist in mycobacteria because a number of secreted proteins have been found to be the products of genes that code for typical $\mathrm{N}$-terminal signal sequences (Young et al., 1992; Orme et al., 1993). Moreover, recently a variety of signal-sequence-encoding genes have been identified by fusions with a leaderless alkaline phosphatase $(p h o A)$ gene and expression in a suitable mycobacterial host (Lim et al., 1995). In this study, we have extended this approach by investigating the usefulness of gene fusions with a leaderless $\beta$-lactamase gene and expression in Escherichia coli. Selection for export-competent signals by both PhoA and $\beta$-lactamase fusions depends on the principle that the enzyme must be translocated across the cytoplasmic membrane into the periplasm; PhoA is inactive in the cytoplasm, and cytoplasmic $\beta$-lactamase cannot protect cells against 
ampicillin-induced lysis (Broome-Smith et al., 1990). However, $\beta$-lactamase gene fusions have been shown to provide an informative alternative to $p h o A$ fusions in analysing the membrane topology of secreted proteins in bacteria and in selecting for diverse signal-sequenceencoding genes (Broome-Smith \& Spratt, 1986; Smith et al., 1987; Broome-Smith et al., 1990; Prinz \& Beckwith, 1994; Reeves et al., 1994).

We report that gene fusions with a leaderless $\beta$-lactamase are indeed useful in identifying signal-sequence-encoding $M$. tuberculosis genes and we demonstrate that M. tuberculosis signal sequences are able to direct the secretion of $\beta$-lactamase in a Gram-negative organism, E. coli.

\section{METHODS}

Bacteria, plasmids and culture conditions. All plasmid and library constructions and signal sequence selections were performed in E. coli XL-1 Blue (supE44 hsdR17 recA2 gyrA46 thi relA1 lac $\mathrm{F}^{\prime}$ ) (Sambrook et al., 1989) as host strain. pGB14 was a gift from Jan M. van Dijl (Groningen Biomolecular Sciences and Biotechnology Institute, Haren, The Netherlands); pGB14T and pGB14TC were generated as described below. pGEX2T was from Pharmacia; pBluescript (pBS) and pBR329 were from Stratagene. E. coli transformed with pGB14T or pGB14TC was grown on LB-agar plates containing $200 \mu \mathrm{g}$ erythromycin $\mathrm{ml}^{-1}$ or $30 \mu \mathrm{g}$ chloramphenicol $\mathrm{ml}^{-1}$, respectively. Screening for $M$. tuberculosis DNA- $\beta$ lactamase gene fusions was performed on LB-agar plates containing $70 \mu \mathrm{g}$ IPTG $\mathrm{ml}^{-1}$ and 50-1000 $\mu \mathrm{g}$ ampicillin $\mathrm{ml}^{-1}$.
Plasmid constructions. pGB14 is an export signal selection vector that is based on pUC13 and contains a $5^{\prime}$-truncated $E$. coli TEM $\beta$-lactamase gene (lacking the signal sequence, translational start site and promoter), an erythromycin resistance $\left(\mathrm{Em}^{\mathrm{r}}\right)$ gene and a multiple cloning site (MCS) upstream of the $\beta$-lactamase gene (Smith et al., 1987; PerezMartinez et al., 1992) (Fig. 1). pGB14T was constructed by cloning a Tac promoter into the unique EcoRI site in the MCS of pGB14. The Tac promoter with suitable EcoRI sites was generated by PCR amplification of a $114 \mathrm{bp}$ fragment of the Tac promoter in pGEX2T, using the forward primer Tac1B ( $5^{\prime}$-AGATCTGAATTCGGTTCTGGC-3') and reverse primer Tac2 (5'-CAGCTGGAATTCGTGTGAAAT-3'). pGB14TC is a derivative of $\mathrm{pGB14T}$ in which the $\mathrm{Em}^{\mathrm{r}}$ gene has been replaced with a chloramphenicol resistance $\left(\mathrm{Cm}^{\mathrm{r}}\right)$ gene. pGB14T was digested with $H p a I$ at a site located within the $\mathrm{Em}^{\mathrm{r}}$ gene and ligated to a CfoI-digested, $1 \cdot 2-\mathrm{kb} \mathrm{Cm}^{\mathrm{r}}$ gene from pBR329 (Fig. 1).

Construction of $\boldsymbol{M}$. tuberculosis genomic libraries. Genomic DNA from $M$. tuberculosis H37Rv (a gift from John $\mathrm{T}$. Belisle, Colorado State University, Fort Collins, CO, USA) was digested with Sau3A and ligated into pGB14T or pGB14TC digested with $B a m \mathrm{HI}$ and treated with calf intestinal phosphatase, at an insert to vector ratio of $2: 1(\mathrm{w} / \mathrm{w})$; alternatively, the genomic DNA was digested with either Hae3 or RsaI and ligated into SmaI-digested vectors. Ligation mixtures were transformed into E. coli XL-1 Blue rendered competent by the $\mathrm{CaCl}_{2} / \mathrm{MgCl}_{2}$ method, or by electroporation, and signal sequence- $\beta$-lactamase gene fusions were selected by direct plating of the transformed $E$. coli on 50-100 $\mu \mathrm{g}$ ampicillin $\mathrm{ml}^{-1}$.

DNA methods and sequence data analyses. DNA manipulations were carried out using standard techniques (Sambrook

Table 1. Internet servers used in the analysis of $M$. tuberculosis DNA- $\beta$-lactamase gene fusions

\begin{tabular}{|c|c|c|}
\hline Server & Description & URL \\
\hline \multicolumn{3}{|l|}{ Database searches } \\
\hline NCBI BLAST & $\begin{array}{l}\text { National Center for Biotechnology } \\
\text { Information; gapped BLASTP/BLASTN/ } \\
\text { TBLASTN searches of all non-redundant } \\
\text { peptide and nucleotide sequence } \\
\text { databases }\end{array}$ & $\begin{array}{l}\text { http://www.ncbi.nlm.nih.gov/cgi-bin/BLAST/nph- } \\
\text { newblast? Jform }=0\end{array}$ \\
\hline TIGR TBLASTN & TBLASTN searches of TIGR contigs & http://www.ncbi.nlm.nih.gov/cgi-bin/BLAST/nph-tigrbl \\
\hline TIGR BLASTN & $\begin{array}{l}\text { BLASTN searches of Sanger and TIGR } \\
\text { contigs }\end{array}$ & http://ziggy.sanbi.ac.za/tb/tbsearch.htm \\
\hline $\begin{array}{l}\text { Sanger Centre M.tb. } \\
\text { BLAST }\end{array}$ & $\begin{array}{l}\text { BLAST searches of Sanger Centre TB } \\
\text { database }\end{array}$ & $\begin{array}{l}\text { http://www.sanger.ac.uk/Projects/M_tuberculosis/ } \\
\text { blast_server.shtml }\end{array}$ \\
\hline MycDB BLAST & $\begin{array}{l}\text { BLAST searches of Integrated } \\
\text { Mycobacterium Database (Institut } \\
\text { Pasteur) }\end{array}$ & $\begin{array}{l}\text { http://kiev.physchem.kth.se/MycDB/ } \\
\text { seqsearch_form.html }\end{array}$ \\
\hline \multicolumn{3}{|l|}{ Sequence analysis tools } \\
\hline ExPASy & $\begin{array}{l}\text { Expert Protein Analysis System; general } \\
\text { protein analysis tools }\end{array}$ & http://expasy.hcuge.ch/www/tools.html \\
\hline TMPred & $\begin{array}{l}\text { TM domain predictions; under ExPASy } \\
\text { tools }\end{array}$ & http://ulrec3.unil.ch/software/TMPRED_form.html \\
\hline ExPASy compute MW & $\begin{array}{l}\text { Molecular weight predictions; under } \\
\text { ExPASy tools }\end{array}$ & http://expasy.hcuge.ch/ch2d/pi_tool.html \\
\hline SignalP & $\begin{array}{l}\text { Signal peptide motif and cleavage site } \\
\text { prediction }\end{array}$ & http://www.cbs.dtu.dk/services/SignalP/ \\
\hline Genestream ALIGN & Sequence alignment tool & http://genome.eerie.fr/bin/align-guess.cgi \\
\hline
\end{tabular}


et al., 1989), or modified as described previously (Da Silva Tatley \& Steyn, 1993). All DNA sequencing was performed on double-stranded plasmid DNA using the Sequenase protocol (version 2.0, USB), or by automated sequencing on an ALF Express Sequenator. M. tuberculosis DNA inserts were sequenced directly in plasmids pGB14T or pGB14TC using primers Tac1B (forward) and Bla (reverse, complementary to $5^{\prime}$ end of TEM $\beta$-lactamase, $5^{\prime}$-CAGCATCTTTTACTTTC$3^{\prime}$ ), or after subcloning EcoRI/XbaI-digested inserts into pBS and using universal end-labelled primers. Insert DNA sequences were translated in three reading frames (forward direction with respect to the $\beta$-lactamase gene) and the ORF in-frame with the $\beta$-lactamase gene (Fig. 2) was identified. Insert ORFs were then searched against sequence databases and analysed for sequence motifs using the Internet servers listed in Table 1 . The primary databases were the $M$. tuberculosis genome sequences released by The Institute for Genomic Research (TIGR) and the Sanger Centre.

Western blot analyses of fusion proteins. pGB14T(H37Rv)transformed, ampicillin-resistant $\left(\mathrm{Amp}^{r}\right)$ E. coli were grown in LB broth containing $100 \mu \mathrm{g}$ ampicillin $\mathrm{ml}^{-1}$ to $\mathrm{OD}_{600} 0.5$, induced with $0.3 \mathrm{mM}$ IPTG for $2 \mathrm{~h}$ and centrifuged at 4000 r.p.m. The supernatants were concentrated 16 -fold in a Centricon ( $30 \mathrm{kDa}$ cut-off; Amicon) and saved as the culture filtrate fraction. The cells were divided into three fractions. (a) The pellet was resuspended in buffer A $(20 \mathrm{mM}$ Tris $/ \mathrm{HCl}$, $\mathrm{pH} 7 \cdot 4,200 \mathrm{mM} \mathrm{NaCl}, 1 \mathrm{mM}$ EDTA), frozen at $-20^{\circ} \mathrm{C}$, thawed and sonicated (six $15 \mathrm{~s}$ pulses) and centrifuged at 8500 r.p.m., after which the supernatant was saved as the soluble cell fraction. (b) The pellet from (a) was resuspended in buffer $\mathrm{A}$ and saved as the insoluble cell fraction. (c) The cells were resuspended in $30 \mathrm{mM}$ Tris $/ \mathrm{HCl}, \mathrm{pH} 8.0$, containing $20 \%(\mathrm{w} / \mathrm{v})$ sucrose, adjusted to $1 \mathrm{mM}$ EDTA, incubated with shaking for $10 \mathrm{~min}$ at room temperature, centrifuged at 8500 r.p.m. for $10 \mathrm{~min}$ and the pellet resuspended in ice-cold $5 \mathrm{mM} \mathrm{MgSO}_{4}$; after incubation on ice with shaking for $10 \mathrm{~min}$, the suspension was centrifuged as before and the supernatant was saved as the periplasmic fraction.

The various cell fractions were mixed with SDS sample buffer and resolved by SDS-PAGE on a $10 \%(\mathrm{w} / \mathrm{v})$ polyacrylamide gel. Electrophoresed proteins were transblotted onto Hybond$C$ nitrocellulose filters (Amersham) under standard conditions (see Hoppe et al., 1997). The filters were incubated in blocking

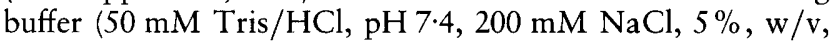
skimmed milk powder, $0.1 \%$ Tween 20 ) for $1.5 \mathrm{~h}$ at room temperature, and then incubated with rabbit anti-ampicillinase IgG (CP Laboratories; 1:1000 in blocking buffer) for $1 \mathrm{~h}$ at room temperature. The blots were washed in blocking buffer without skimmed milk powder (TBS/Tween), incubated with peroxidase-conjugated anti-rabbit IgG (ECL Western blotting system, Amersham; $1: 1500$ in TBS/Tween) for $1 \mathrm{~h}$ at room temperature, washed again in TBS/Tween, and then treated with ECL detection reagents and exposed to photographic film, as recommended by the manufacturer.

\section{RESULTS}

\section{Construction of plasmids PGB14T and PGB14TC}

pGB14 has proven useful in identifying signal-sequenceencoding genes from the Gram-positive bacteria Bacillus subtilis and Lactococcus lactis by selection in an E. coli background (Smith et al., 1987; Perez-Martinez et al., 1992). However, this vector may not function well with $M$. tuberculosis inserts because the leaderless $\beta$-lactamase gene in pGB14 also lacks a promoter and myco- bacterial promoters are, in general, poorly recognized by the E. coli transcriptional apparatus (Das Gupta et al., 1993). We therefore introduced the efficient, IPTGinducible $E$. coli Tac promoter, to generate pGB14T. Selection for pGB14-transformed E. coli depends on erythromycin resistance, which is a poor marker in Gram-negative organisms; we found that even at $200 \mu \mathrm{g}$ erythromycin $\mathrm{ml}^{-1}$, selection for true $\mathrm{Em}^{\mathrm{r}}$ proved difficult due to a high rate of spontaneous low-level resistance. Hence we constructed pGB14TC as an alternative vector, in which the $\mathrm{Em}^{\mathrm{r}}$ gene was interrupted by a $\mathrm{Cm}^{\mathrm{r}}$ cassette. As expected, growth on chloramphenicol facilitated selection for E. coli (pGB14) transformants.

\section{Construction in $E$. coli of a library of $\beta$-lactamase fusions with $M$. tuberculosis genomic DNA fragments}

Genomic DNA from $M$. tuberculosis H37Rv digested with Sau3A, Hae3 or RsaI was ligated into the MCS of pGB14T and pGB14TC between the Tac promoter and the leaderless $\beta$-lactamase gene. The highest transformation efficiency of E. coli with the ligation products was achieved with electroporation (10-100-fold greater than transformation of $\mathrm{CaCl}_{2}$-competent cells). However, even with electroporation, transformations were only in the order of $2 \times 10^{7}$ c.f.u. per $\mu \mathrm{g}$ pGB14T(H37Rv) or pGB14TC(H37Rv) DNA. Transformation with the pGB14T or pGB14TC vectors alone gave similar results, compared to approximately $10^{9}$ c.f.u. per $\mu \mathrm{g}$ for $\mathrm{pBS}$, indicating that pGB14-based vectors are inefficient transformation substrates.

Generally, E. coli transformed with pGB14T(H37Rv) or pGB14TC $(\mathrm{H} 37 \mathrm{Rv})$ were selected directly on plates containing 50-100 $\mu \mathrm{g}$ ampicillin $\mathrm{ml}^{-1}$, and an aliquot of each batch of transformants was grown on plates containing $200 \mu \mathrm{g}$ erythromycin $\mathrm{ml}^{-1}$ or $30 \mu \mathrm{g}$ chloramphenicol $\mathrm{ml}^{-1}$, respectively, to assess transformation efficiencies. All Amp ${ }^{r}$ clones were tested on erythromycin or chloramphenicol plates, as appropriate, to select for true transformants. From a total of $6000 \mathrm{Em}^{\mathrm{r}}$ clones and $8000 \mathrm{Cm}^{\mathrm{r}}$ clones, $10 \mathrm{Amp}^{\mathrm{r}} / \mathrm{Em}^{\mathrm{r}}$ and $5 \mathrm{Amp}^{\mathrm{r}} / \mathrm{Cm}^{\mathrm{r}}$ transformants, respectively, were isolated.

\section{Analysis of $\boldsymbol{M}$. tuberculosis DNA- $\beta$-lactamase fusions conferring Amp' in E. coli}

Twelve of the Amp ${ }^{r}$ clones were tested for their level of $A m p^{r}$ and all were resistant to up to $1 \mathrm{mg}$ ampicillin $\mathrm{ml}^{-1}$ on LB plates. Insert sizes ranged from 350 to $3000 \mathrm{bp}$. Ten inserts from $\mathrm{Amp}^{\mathrm{r}} / \mathrm{Em}^{\mathrm{r}}$ and $\mathrm{Amp}^{\mathrm{r}} / \mathrm{Cm}^{\mathrm{r}}$ clones were sequenced and the results are summarized in Table 2. To facilitate analysis, insert DNA sequences were translated and the ORF in-frame with the $\beta$ lactamase gene was identified. Comparison of the deduced amino acid sequences with known sequences in databases enabled complete identification in all cases (Fig. 2). pGB14T-L4 and pGB14TC-W were found to be identical to the $M$. tuberculosis antigen $85 \mathrm{~A}$ and $85 \mathrm{C}$ genes, respectively (Fig. 2a, b). pGB14T-L4 showed $100 \%$ identity over 180 amino acid residues with 
Table 2. Characteristics of $M$. tuberculosis DNA- $\beta$-lactamase gene fusions that confer Ampr in E. coli

Plasmids containing $\beta$-lactamase gene fusions that confer $\mathrm{Amp}^{\mathrm{r}}$ in $E$. coli were purified, analysed by restriction mapping and sequenced as indicated. Sequence data were searched for homologies to sequences in the $M$. tuberculosis genome (see Table 1). All ten transformants were able to grow on agar plates containing $1000 \mu \mathrm{g}$ ampicillin $\mathrm{ml}^{-1}$.

\begin{tabular}{|lrrlc|}
\hline $\begin{array}{l}\text { Recombinant } \\
\text { plasmid }\end{array}$ & $\begin{array}{c}\text { Insert size } \\
\text { (bp) }\end{array}$ & $\begin{array}{c}\text { G }+ \text { C } \\
\text { content } \\
(\mathbf{m o l} \%)\end{array}$ & Identity* & $\begin{array}{c}\text { Size of mature } \\
\text { protein (kDa) }\end{array}$ \\
\hline pGB14T-L4 & 921 & $67 \cdot 2$ & Ag85A & 32 \\
pGB14TC-W & 350 & $61 \cdot 4$ & Ag85C & 32 \\
pGB14T-P & 926 & $69 \cdot 7$ & Hypothetical ORF, & 52 \\
& & & probable PBP (Pmtb1) & 26 \\
pGB14T-B & 890 & $56 \cdot 9$ & Hypothetical ORF (Bmtb1) & 13 \\
pGB14TC-X & 928 & $62 \cdot 4$ & Hypothetical ORF (Xmtb1) & 15 \\
pGB14TC-V & 604 & $61 \cdot 5$ & Hypothetical ORF (Vmtb1) & 30 \\
pGB14T-O2 & 914 & $62 \cdot 2$ & Hypothetical ORF (O2mtb1) & $7 \cdot 8$ \\
pGB14T-O1 & 500 & $57 \cdot 7$ & Hypothetical ORF (O1mtb1) & $7 \cdot 8$ \\
pGB14T-B3 & 500 & $57 \cdot 7$ & Identical to O1mtb1 & 33 \\
pGB14T-Q5 & 3000 & $54 \cdot 5$ & E. coli cyt. C biogen. protein & \\
\hline
\end{tabular}

"Identities $(\geqslant 97 \%)$ to M. tuberculosis genes. In parentheses are our designations (see Fig. 2 for further information).

†Predicted molecular masses of putative proteins after cleavage of potential signal peptides.

Ag85A; pGB14TC-W showed $100 \%$ identity over 40 residues with $\mathrm{Ag} 85 \mathrm{C}$. Both inserts included the entire signal sequence, translational start site and upstream ribosome-binding site.

A group of four inserts was found to be homologous to mycobacterial genes that comprise hypothetical ORFs encoding one or more potential membrane-interaction domains (in addition to the signal peptides) (Fig. 3).

The first insert, pGB14T-P, was $98 \%$ identical (176 out of 180 amino acid residues) to the product of an unannotated, hypothetical ORF at positions 4244-3573 on contig gmt 18 of the TIGR $M$. tuberculosis genome, which we have designated Pmtb1 for ease of reference (Fig. 2c). Pmtb1, in turn, was $75 \%$ identical (168 out of 225 amino acid residues) to the product of an unannotated, hypothetical ORF on cosmid B1529 (positions 19336-20019) of the Mycobacterium leprae genome (GenBank accession number L78824) (Pmlep1 in Fig. 2c). Using the recently released gapped BLAST protein database search program (BLASTP 2.0.2, Table 1), Pmtb1 was found to be $35 \%$ identical to PcbR, a lowaffinity penicillin-binding protein (PBP) from Streptomyces clavuligerus (Paradkar et al., 1996; GenBank accession number U56256). A lower degree of identity $(31 \%)$ was found for two M. tuberculosis ORFs also annotated as low-affinity PBPs (MTCY10H4.16c and MTCY270.05; EMBL accession numbers Z80233 and Z95388). Both Pmtb1 and Pmlep1 contained potential membrane lipoprotein lipid attachment sites (as predicted by GCG motifs; see also Pugsley, 1993); Pmtb1 contained a potential TM domain near its $\mathrm{C}$ terminus (Fig. 3a).
The second insert, pGB14TC-V, was $98 \%$ identical (83 out of 84 residues) to the protein encoded by an annotated, hypothetical ORF (MTCY493.19) on $M$. tuberculosis cosmid Y493 (positions 26656-27264, EMBL accession number Z95844), which we have designated Vmtb1 (Fig. 2d). Vmtb1 was a 202 amino acid preprotein that contained an extended apolar, glycine- and proline-rich central domain (residues 60-156) that was not typical of a TM domain but may participate in hydrophobic interactions (Fig. 3b).

The third insert, pGB14TC-X, was a chimaera consisting of two unrelated DNA fragments ligated at a HaeIII site. The $5^{\prime}$ fragment encoded a signal peptide that was $100 \%$ identical ( 23 out of 23 residues) to the product of an unannotated, hypothetical ORF in contig gmt234 (positions 5559-5627) of the TIGR $M$. tuberculosis genome, referred to here as Xmtb1 (Fig. 2e). Xmtb1 was, in turn, $75 \%$ identical (104 out of 137 residues) to a hypothetical, $16.9 \mathrm{kDa} M$. leprae protein (SWISS-PROT accession number P54880) (Xmlep1 in Fig. 2e). Further, Xmlep1 was $44 \%$ identical (65 out of 147 residues) to a hypothetical, $15.9 \mathrm{kDa}$ M. tuberculosis protein (SWISS-PROT accession number Q11170) (Xmtb2 in Fig. 2e), which, lastly, was $42 \%$ identical (59 out of 142 residues) to a third hypothetical M. tuberculosis protein (MTCY04D9.16c on cosmid SCY04D9, EMBL accession number Z84725) (Xmtb3 in Fig. 2e). Two of the homologues, Xmlep1 and Xmtb3, contained putative TM domains near their $\mathrm{C}$ termini (Fig. 3c).

The fourth insert in this group, pGB14T-O2, was $100 \%$ identical to the product of an unannotated, hypothetical ORF in $M$. tuberculosis contig gmt551 (positions 
(a) pGB14T-I4

Ag85A

(b)

pGB14TC-W

Ag85C

(c)

PGB14T-P

Pmtbl

Pmlep1

(d) PGB14TC-V

Vmtb 1

(e)

PGB1 4TC-X

Xmtb1

Xmlep1

$\mathrm{xmtb} 2$

Xmtb3

(f)

PGB14T-02

o2mtb1

(g)

PGB1 4T-B

Bintb1

Bmtb2

Bmlep1

(h) PGB1 4T-O1

olmtb1

MQLVDRVRGAVTGMSRRLVVGAVGAALVSGLVGAVGGTATAGAFSRPGLPVEYLQVPSPSMGRDIKVQFQSGGANSPALYLLD-255-DPL

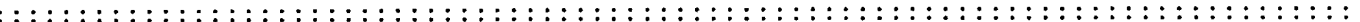
MQLVDRVRGAVTGMSRRLVVGAVGAAIVSGLVGAVGGTATAGAFSRPGLPVEYLQVPSPSMGRDI KVQFQSGGANSPALYLLD

MTFFEQVRRLRSAATTLPRRIAIAAMGAVLVYGLVGTFGGGDPLESTAQACppet lvkvkdaedgl garvgyieldlnsgki lesfrpeer

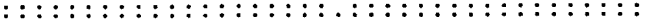
MTFFEQVRRLRSAATTLPRRVAIAAMGAVLVYGLVGTFGGPATAGAFSRPGLPVEYLQVPSASMGRDIKVQFQGGGPHAVYLLDGLRAQDD MVTKTT---IASATSGLLIAVVAMSGCTPRPQGPGPAAEKEFAALAIGDTASAAQLSDNPNEAREALNAAWAGLQAAHLDA-121-DPL

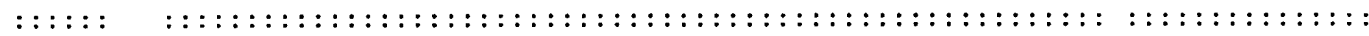
MVTKTT---LASATSGLLLLAVVAMSGCTPRPQGPGPAAEKFFAALAIGDTASAAQLSDNPNEAREXLNAAWAGLQAAHLDA

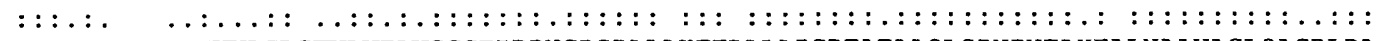
MMVTRTSPGSFVSVVAGLCFVAVIAVSGCTPRPNGPGPAAAKFFDALAIGDTATAAQLSDNPNEAHEALNAAWAGLQAGRLDA

MAIVNRFNIKVIAGAGLFAAAIALSPDAAADPLMTGGYACIQGMAGDAPVAAGDPVAAGGPAAAGACSAALTDMAGVPFVAPGGDPLE

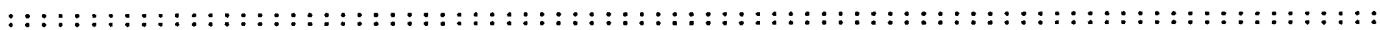
MTLMAIVNRFNIKVIAGAGLFAAAIALSPDAAADPLMTGGYACIQGMAGDAPVAAGDPVAAGGPAAAGACSAALTDMAGVPFVAPGPVPAA

MRTWIPLVILVVVIVGGFTVHRI IGAVALAVDTVPESVRRQVI IQSVLGRVRIPDPIAALGNRMQGHSDPLESTA : : : : : : : : : : : : : : : : : : : : : : : MRTWIPLVILVVVIVGGFTVHRIRGFFGSENRPSYSDTNLENSKPFNPKHLTYEIFGPPGTVADISYFDVNSEPQ

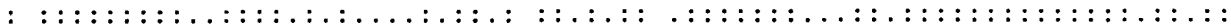
MSKRQRGKGISIFKLLSRIWIPLVILVVLVVGGFVVYRVHSYFASEKRESYADSNLGSSKPFNPKQIVYEVFGPPGTVADISYFDANSDPQ

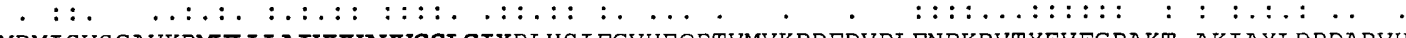
MRMI SVSGAVKRMWLLLAIVVVAVVGGLGIYRLHS I FGVHEQPTVMVKPDFDVPLFNPKRVTYEVFGPAKT-AKIAYLDRDARVH

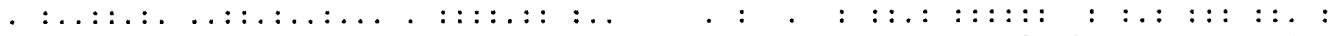
MFGVAKRFWI PMVIVIVVAVAAVTVSRLHSVFGSHQHAPDTGNLD-PIIAFYPKHVLYEVFGPPGTVAS INYLDADAQPH MKPNHAGKI PVHAELWKHGAAADDSVNCMRMLRRLRRATVAAAVWLATVCLVASCANADPLESTAQACppet 1 vkvkdaedq $1 g a$ rVgYie $::::::::::::::::::::::::::::::::::::::::::::::::::::::::::::::::$ : MKPNHAGKI PVHAELWKHGAAADDSVNCMRMLRRLRRATVAAAVWLATVCLVASCANADPLGSATGSVKS IVVGSGDFPESQVIAEI YAQV

MKTTGTTIKLGIVWLVLSVETVMIIVVFGQVRFHHTTGYSAVFTHVSGLRAE IASAERFS IPLAQVSPHDVAEA-46-GDPLESTAQACPP $::::::::::::::::::::::::::::::::::::::::::::::::::$ :

MKTTGTTIKLGIVWLVLSVFTVMIIVVFGQVRFHHTTGYSAVFTHVSGLRAGQFVRAAGVEVGKVAKVTLIDGDKQVLVDFTVDRSLSLDQ

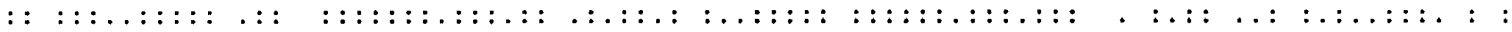
MKITGTVVKLGIVSVVLLFFTVMIIVIFGQMRFDRTNGYTAEFSNVSGLRQGQFVRASGVEIGKVKALHLVDGGRRVRVEFNIDRSVPLYQ

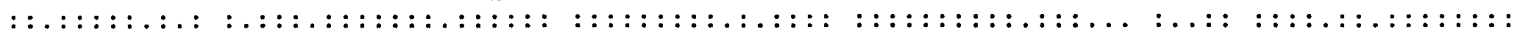
MKLTGTVVRISIFSLVLLLFTVMIIVVFGQMRFGRTNGYTAEFTNISGLRTGQFVRASGVEVGKVNSVALINGGTRVRVKFNVDRSVPLYQ

Fig. 2. Sequence alignments of predicted proteins encoded by export-competent $M$. tuberculosis gene fusions. In each case $(a-h), M$. tuberculosis insert sequences identified with the pGB14T and pGB14TC selection vectors are shown above their respective homologues retrieved from mycobacterial databases (Table 1). Sequences are in the single-letter amino acid code. Only one line of sequence per insert is shown, truncated as necessary (by the number of residues indicated), ending in the underlined sequence (G)DPLESTAQAC (spacer sequence at the fusion junction) followed by ppet/... (start of mature $\beta$-lactamase, in lower-case italics). Hydrophobic sequences that represent potential signal peptides or TM domains are in bold; arrows indicate probable signal peptide cleavage sites in the native proteins, as predicted by SignalP (Table 1). Sequence nomenclature is our own. Sources are as follows (in parentheses are accession numbers; gb, GenBank; emb, EMBL; sp, SWISS-PROT): (a) Ag85A (gb M27016); (b) Ag85C (sp P31953); (c) Pmtb1, unannotated ORF, contig gmt18, 4244-3573 (TIGR); Pmlep1, unannotated ORF, M. leprae cosmid B1529, 19336-20019 (gb L78824); (d) Vmtb1, ORF labelled MTCY493.19 on cosmid Y493, 26656-27264 (emb 295844); (e) (note that pGB14T-X was a chimaera, the $5^{\prime}$ sequence encoding a signal peptide that was identical to that of Xmtb1; the $3^{\prime}$ sequence, in italics, was not analysed further) Xmtb1, unannotated ORF, contig gmt234, 5559-5627 (TIGR); Xmlep1, ORF labelled U1740W on M. leprae cosmid B174, complement 24139-24603 (gb U15183); Xmtb2, ORF labelled CY20G9.33, on cosmid SCY20G9, 31159-31602 (emb Z77162); Xmtb3, ORF labelled MTCY04D9.16c, on cosmid SCY04D9, 14771-15199 (emb Z84725); (f) O2mtb1, unannotated ORF, contig gmt551, 5197-4167 (TIGR); (g) (pGB14T-B was also chimaeric; $3^{\prime}$ sequence, in italics, was not analysed) Bmtb1, ORF labelled MTCY19H5.32c on cosmid SCY19H5, 24949-25776 (emb Z97182); Bmtb2, ORF labelled MTCI28.10 on cosmid 128, 8981-10021 (emb Z97050); Bmlep1, unannotated ORF on M. leprae cosmid B983, 9760-10797 (gb L78828); (h) 01mtb1, unannotated ORF on contig gmt374, 1342-1040 (TIGR). 


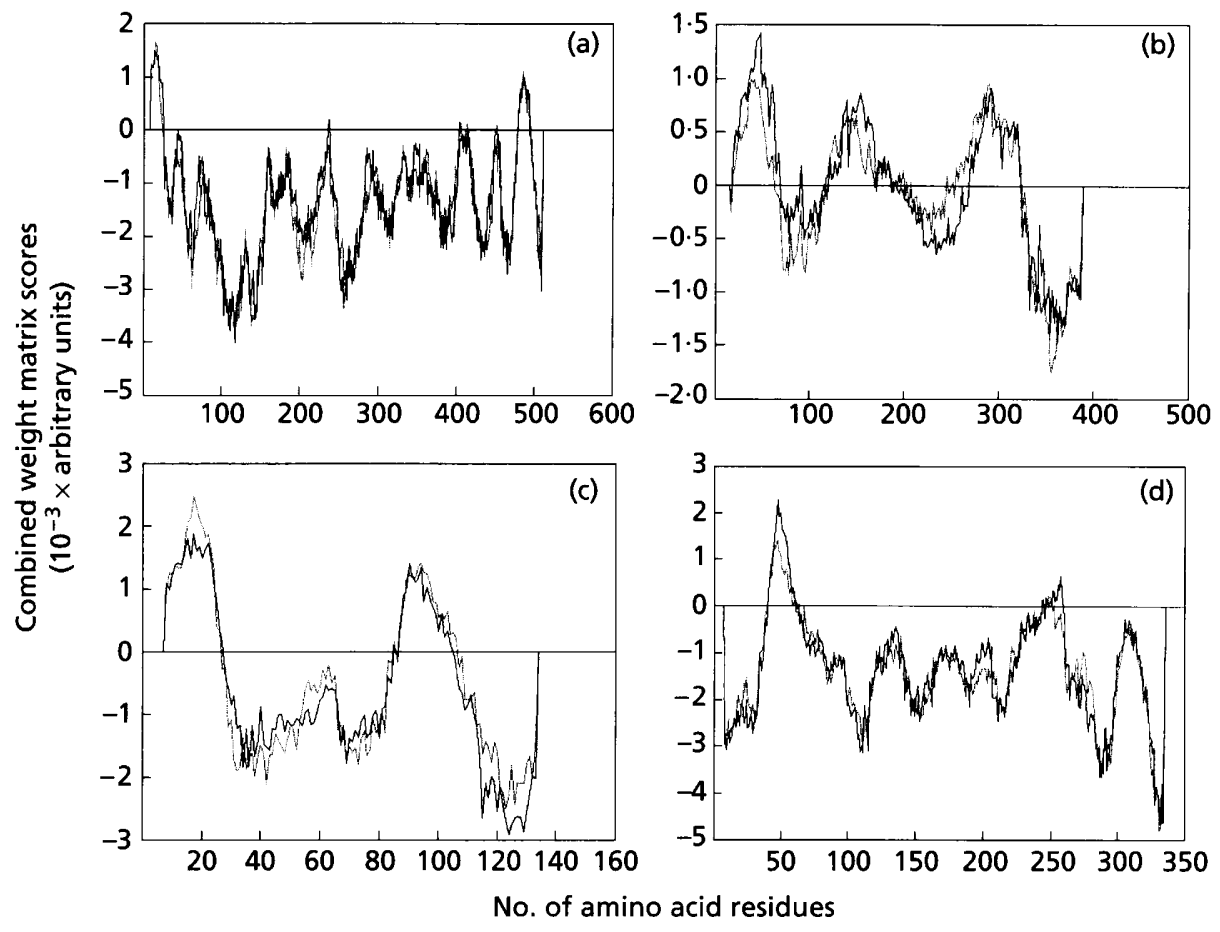

Fig. 3. Hydropathy plots of putative $M$. tuberculosis exported proteins with possible membrane-interaction domains. Identities of the sequences are described in Fig. 2. Plots were drawn with the program TMPred (Table 1). Combined weight matrix scores of $>500$ indicate possible TM regions. (a) Pmtb1, (b) Vmtb1, (c) Xmtb3, (d) O2mtb1.

5197-4167) (O2mtb1 in Fig. 2f). O2mtb1 did not contain a typical cleavable signal sequence. A stretch of 21 hydrophobic and apolar residues that could serve as an export signal was preceded by at least $37 \mathrm{~N}$-terminal residues, including three negatively charged residues and a cluster of five arginines (Fig. 2f), which is very uncharacteristic of cleavable signal sequences (Pugsley, 1993). O2mtb1 may be a type II TM protein with an uncleaved signal peptide acting as a true TM segment (Fig. 3d). Apart from this exception, all Amp ${ }^{\mathrm{r}}$-conferring $\beta$-lactamase gene fusions that were sequenced coded for readily identifiable signal sequences, defined as $\mathrm{N}$ terminal extension sequences that direct export across the cytoplasmic membrane and characterized by shared physico-chemical features (Pugsley, 1993; Izard \& Kendall, 1994) (Fig. 2). Thus, Pmtb1, Vmtb1, Xmtb1, $\mathrm{O} 2 \mathrm{mtb} 1$ and homologues represent a group of hypothetical exported mycobacterial proteins that contain putative TM, hydrophobic, or membrane-interaction domains.

As was found for pGB14T-P and pGB14TC-X, pGB14T$\mathrm{B}$ was homologous to several mycobacterial genes. pGB14T-B was $100 \%$ identical (50 out of 50 residues) to a hypothetical M. tuberculosis protein (MTCY19H5.32c on cosmid SCY19H5, EMBL accession number Z97182) (Bmtb1 in Fig. $2 \mathrm{~g}$ ), which was $65 \%$ identical (168 out of 257 residues) to a second hypothetical $M$. tuberculosis protein (MTCI28.10 on cosmid I28, EMBL accession number Z97050) (Bmtb2 in Fig. 2g). Bmtb2, in turn, was $75 \%$ identical ( 260 out of 346 residues) to the product of an unannotated, hypothetical ORF in the M. leprae genome (cosmid B983, positions 9760-10797, GenBank accession number L78828; Bmlep1 in Fig. $2 \mathrm{~g}$ ). The functions of each of these putative exported proteins is unknown. Of note is that Bmtb2 contained four potential N-linked glycosylation sites (NXS/T) typical of eukaryotic exported proteins.

The insert in pGB14T-O1 was cloned independently on two occasions, as pGB14T-O1 and -B3, perhaps because it encoded an extremely favourable signal peptide (Fig. $2 \mathrm{~h}$ ), or because multiple copies of the gene were present in the genome. pGB14T-O1 was $100 \%$ identical (44 out of 44 residues) to the product of an unannotated, hypothetical ORF in M. tuberculosis contig gmt374 (positions 1324-1040) in the TIGR genome (O1mtb1 in Fig. 2h). Lastly, the insert in pGB14T-Q5 (at $3000 \mathrm{bp}$ the largest) was found to be $100 \%$ identical (193 out of 193 residues) to the $E$. coli cytochrome C-type biogenesis protein CCMH precursor, which has an excellent $\mathrm{N}$ terminal signal peptide (not shown). This is presumably an E. coli chromosomal DNA contaminant that was copurified and codigested with the pGB14T plasmid preparation prior to $M$. tuberculosis DNA insert ligation.

\section{Immunodetection of $\boldsymbol{\beta}$-lactamase fusions}

Cell fractions of $A m p^{r} E$. coli transformed with the clones described in Fig. 2 were probed by Western blotting using an anti-TEM $\beta$-lactamase antibody. 

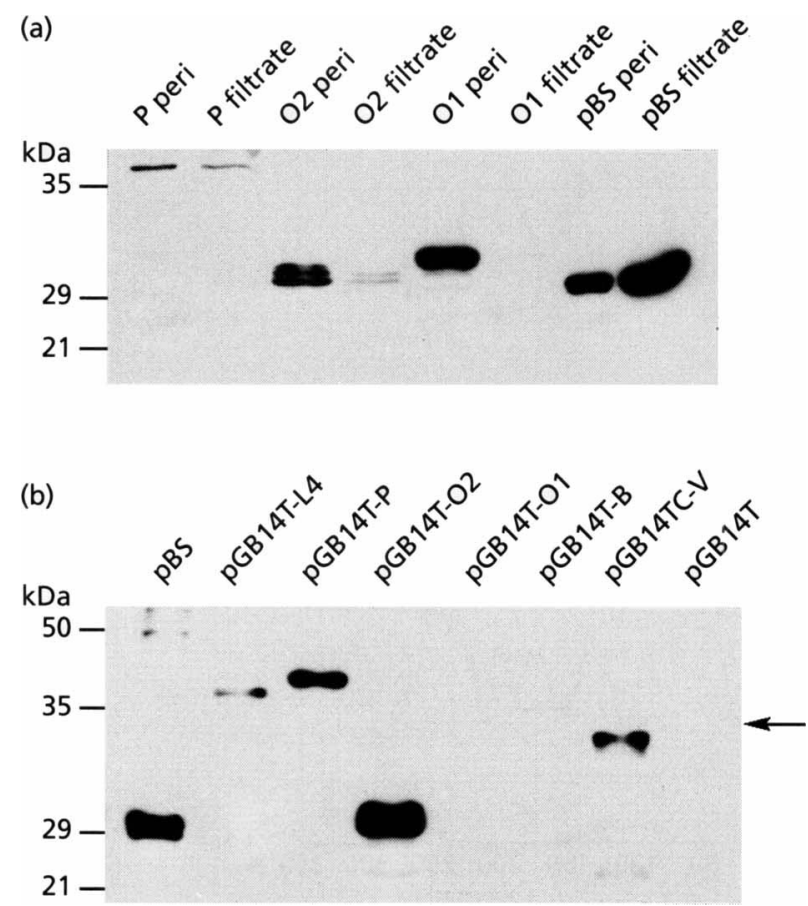

Fig. 4. Western blots of Ampr, pGB14T(H37Rv)-transformed $E$. coli fractions probed with an anti- $\beta$-lactamase antibody. $E$. coli cell fractions were prepared as described in Methods. (a) Periplasmic (peri) and culture filtrate fractions, respectively, of E. coli transformed with $\mathrm{pGB} 14 \mathrm{TT}-\mathrm{P}$ ( $\mathrm{P}$ peri, $\mathrm{P}$ filtrate), -O2 (O2 peri, $\mathrm{O} 2$ filtrate), -01 (O1 peri, $\mathrm{O} 1$ filtrate) and $\mathrm{pBS}$ ( $\mathrm{pBS}$ peri. pBS filtrate). (b) Insoluble fractions of $E$. coli transformed with the indicated vectors; no band was seen in the PGB14T-O1 lane on this blot. The arrow on the right indicates the position of an immunoreactive band in the pGB14T-B lane that was seen clearly on the original blot. Molecular mass marker positions (in $\mathrm{kDa}$ ) are indicated.

Analysis of the periplasmic and culture filtrate fractions revealed fusion proteins with relative mobilities that in most cases were in good agreement with predicted molecular masses for the mature proteins after signal peptide cleavage, as follows (predicted masses in parentheses) : pGB14T-W, $32 \mathrm{kDa}(31)$; -P, $45 \mathrm{kDa}(49)$; -V, $35 \mathrm{kDa}(35)$; -X, $34 \mathrm{kDa}(34)$; -O2, $31 \mathrm{kDa}(30)$; -O1, $32 \mathrm{kDa}(30.5)$ (Fig. $4 \mathrm{a}$; pGB14T-W, $-\mathrm{V}$ and $-\mathrm{X}$ not shown). No immunoreactive band was detected in extracts of $E$. coli transformed with vector (pGB14T) alone; as positive control, pBS-transformed E. coli extracts revealed a protein of the expected molecular mass (30 kDa; predicted, $29 \mathrm{kDa}$ ) (Fig. 4a). Two of the transformants gave fusion proteins with smaller than expected masses: pGB14T-L4 revealed a protein of $38 \mathrm{kDa}$ (predicted, 46.3) and pGB14T-B gave $35 \mathrm{kDa}$ (39.5) (Fig. 4b). This discrepancy may have resulted from signal peptide cleavage at an alternative site or from secondary proteolytic processing of the mature fusion protein. Anomalously low fusion protein masses have been observed previously with $\alpha$-amylase and PhoA fusions (Smith et al., 1987; Lim et al., 1995). Western blot analysis of the insoluble (Fig. 4b) and soluble (not shown) cell fractions revealed fusion proteins identical in size to those seen in the periplasmic and culture filtrate fractions. Hence we were unable to detect the unprocessed pre-forms, except as occasional faint traces, including a $32 \mathrm{kDa}$ immunoreactive band in the $\mathrm{pBS}$ fraction that presumably corresponded to the unprocessed form (faintly visible in Fig. 4b). We conclude that under these experimental conditions, signal peptide cleavage was so efficient that the vast majority of detectable fusion proteins was processed.

\section{DISCUSSION}

The mycobacterial protein export machinery has not been characterized. Although they are formally considered as members of the Gram-positive family, mycobacteria have unusual cell walls that contain unique features. Most notable is the presence of an arabinogalactan-mycolic acid superpolymer that is covalently linked, and external, to the peptidoglycan. The mycolic acids of this superpolymer have been proposed to constitute the inner leaflet of a pseudo outer membrane; the outer leaflet is provided by various non-covalently associated phospholipids and glycolipids (Brennan \& Draper, 1994). Thus, the mycobacterial cell wall bears a superficial resemblance to the lipid-rich Gram-negative envelope, although the mycobacterial envelope is markedly waxy and much less fluid (Liu et al., 1996). It can be anticipated, therefore, that some of the special problems of protein export in Gram-negative organisms are also encountered in mycobacteria, particularly with regard to targeting to various cell wall compartments, including complete secretion into the extracellular milieu (Pugsley, 1993). These considerations notwithstanding, it seems likely that the first step in protein translocation, export across the cytoplasmic membrane, which is common to the general secretory pathways of both Gram-positive and Gram-negative organisms, is also shared by mycobacteria. Indeed, many of the genes encoding secreted mycobacterial proteins encode typical $\mathrm{N}$-terminal signal sequences (Young et al., 1992), indicating that mycobacteria probably possess a standard Sec-dependent export pathway. A search of annotated genes in the $M$. tuberculosis genome (Sanger Centre) revealed homologues of $\sec A$, secB, secD, secE and secF [EMBL accession numbers and loci Z95121 (MTCY20B11.15c), Z79701 (MTCY277.40), Z77724 (MTCY227.14), Z92772 (MTCY20H10.19) and Z77724 (MTCY227.15), respectively]. The Mycobacterium bovis BCG secY has been reported (GenBank accession number U77912) and we found the $M$. tuberculosis homologue on TIGR contig gmt7540 (positions 12060-13382).

In efforts to gain further insights into protein secretion in M. tuberculosis we have explored the usefulness of a signal sequence selection vector for the identification and characterization of mycobacterial signal-sequenceencoding genes in an E. coli host. We have exploited a vector relying on $\beta$-lactamase gene fusions, which has proved useful in identifying $B$. subtilis and $L$. lactis signal sequence genes in transformed E. coli (Smith et al., 1987; Perez-Martinez et al., 1992). After modifying the vector by inserting a Tac promoter upstream of the 
leaderless $\beta$-lactamase gene, we were able to isolate a variety of signal sequence genes from an $M$. tuberculosis genomic DNA library. The ability of the selection vector to successfully identify bona fide secreted proteins was evident from clones pGB14T-L4 and -W that contained fragments of the Ag85A and $\mathrm{Ag} 85 \mathrm{C}$ genes, respectively, which together with $\mathrm{Ag} 85 \mathrm{~B}$ constitute the major secreted proteins of the M.tuberculosis complex (Content et al., 1991). Ag85 proteins account for more than $30 \%$ (by weight) of the total extracellular proteins in $M$. $t u$ berculosis culture filtrates (Horwitz et al., 1995).

All but one of the Amp ${ }^{\mathrm{r}} \beta$-lactamase gene fusions that were sequenced were found to encode clearly recognizable signal sequences; the exception (pGB14T-O2) appeared to encode a sequence more typical of type II TM proteins with uncleaved signal peptides. All of the gene fusions tested conferred wild-type levels of $\mathrm{Amp}^{\mathrm{r}}$ (up to $1 \mathrm{mg}$ ampicillin $\mathrm{ml}^{-1}$ on agar plates), indicating that the M. tuberculosis genome contains a number of genes encoding signal sequences that satisfy all the requirements of the E. coli Sec-dependent export machinery. This conclusion is supported by previous data demonstrating that the secreted M. bovis protein MPB70 was efficiently secreted into the periplasm of $E$. coli transformed with the entire MPB70 gene, including the mycobacterial ribosome-binding site, start codon and signal peptide (Hewinson \& Russell, 1993). The MPB70 signal peptide also directed the export of the $19 \mathrm{kDa} M$. bovis antigen in E. coli (Hewinson et al., 1996a). The nature of the selection system used in our experiments will be biased towards the selection of $E$. coli-compatible signal sequences and provides no information on the presence of atypical signal sequences and/or export pathways in M. tuberculosis. Nevertheless, these results argue strongly that a subset of proteins secreted by $M$. tuberculosis is exported by a Sec-dependent pathway which has characteristics similar to the E. coli machinery. This is consistent with the notion that despite differences in detail, the sec-dependent pathways of Gram-positive and Gram-negative bacteria are broadly similar (Pugsley, 1993; Salmond \& Reeves, 1993; Bolhuis et al., 1996).

All of the signal-peptide-encoding DNA fragments sequenced could be matched with database sequences. Nine of ten gave perfect matches with sequences in the $M$. tuberculosis genome (TIGR and Sanger Center databases), whereas one (pGB14T-Q5) contained an $E$. coli chromosomal DNA contaminant. Strikingly, apart from the Ag85 proteins that were recently shown to be mycolyltransferases (Belisle et al., 1997), only one of the other putative exported proteins shown in Fig. 2 could be assigned a function, despite extensive BLAST searches against all of the major databases. Pmtb1 was an unannotated hypothetical ORF that after a gapped BLAST search was found to be $35 \%$ identical to a lowaffinity PBP (PcbR) from $S$. clavuligerus, a protein that belongs to the high-molecular-mass group B PBPs (Paradkar et al., 1996). Low-affinity PBPs of this type may play an important role in $\beta$-lactamase resistance in actinomycetes (Paradkar et al., 1996). Further analysis revealed that Pmtb1 was $31 \%$ identical to two annotated M. tuberculosis low-affinity PBPs, MTCY10H4.16c and MTCY270.05, which were $23 \%$ identical to each other. In contrast to the latter two, Pmtb1, and its M. leprae homologue Pmlep1, contained a signal peptide with features typical of a lipoprotein lipid attachment site (Fig. 2; see Pugsley, 1993). High-molecular-mass PBPs typically contain $\mathrm{N}$-terminal hydrophobic domains that probably function as uncleaved signal peptides and membrane anchors, as has been inferred for PcbR (Paradkar et al., 1996); similar sequences were present in the putative M. tuberculosis PBPs MTCY10H4.16c and MTCY270.05. Interestingly, Pmtb1 was only $6 \mathrm{~kb}$ removed from the gene encoding MPT83 (on contig gmt18 in the TIGR M. tuberculosis genome), which is a known lipoprotein that is expressed by members of the M. tuberculosis complex and which is homologous to, and in turn only $2.4 \mathrm{~kb}$ upstream of, the gene for the secreted M. tuberculosis protein MPT70 (Hewinson et al., 1996b; Vosloo et al., 1997). The functions of MPT83 and MPT70 are unknown, but expression of MPT83 may be elevated during an in vivo $M$. tuberculosis infection (Hewinson et al., 1996b), and MPB70 is an immunodominant $M$. bovis antigen (Hewinson \& Russell, 1993).

Further interesting observations that emerged from analyses of putative proteins encoded by the ORFs identified in our screen (Fig. 2) include the following. Of a set of four homologues, Xmlep1 and Xmtb3 contained a possible TM domain near their $\mathrm{C}$ termini, making them potential type I TM proteins. Together with O2mtb1, a potential type II TM protein, and Vmtb1, a protein containing an extended glycine- and proline-rich apolar domain, Pmtb1, Pmlep1, Xmlep1 and Xmtb3 constitute a group of exported proteins that are potentially associated with the cell membrane or other compartments of the lipid-rich mycobacterial cell wall (Fig. 3). Finally, also of interest was the presence of four potential $\mathrm{N}$-linked glycosylation sites in $\mathrm{Bmtb} 2$. The existence of O-linked glycoproteins in mycobacteria is now well-established (Dobos et al., 1996; Herrmann et al., 1996) and there is evidence for N-linked carbohydrates in the secreted $19 \mathrm{kDa}$ antigen of $M$. tuberculosis (M. Ward, W. Blackstock, M.-P. Gares, D. B. Young \& C. Abou-Zeid, personal communication). The significance of this form of glycosylation in mycobacteria remains to be determined. It is noteworthy that the major outer-membrane protein of Chlamydia trachomatis contains $\mathrm{N}$-linked high-mannose type oligosaccharides that are required for binding and infection of HeLa cells in vitro (Kuo et al., 1996). We have shown recently that surface-exposed glycoconjugates mediate direct and opsonin-enhanced binding of $M$. tuberculosis to various mammalian cells in vitro (Hoppe et al., 1997; Cywes et al., 1997). Thus the possible involvement of mycobacterial glycoproteins in such processes warrants further investigation.

It has been shown that alkaline phosphatase ( $p h o A)$ gene fusions are useful in studying protein export in mycobacteria (Timm et al., 1994) and that this system 
allows identification of M. tuberculosis genes encoding secreted proteins in an M. smegmatis host (Lim et al., 1995; Jackson et al., 1997). PhoA reporter constructs gave a yield of $0.09 \% \mathrm{Amp}^{\mathrm{r}}$ transformants from an $M$. tuberculosis genomic DNA library (Lim et al., 1995), compared to our rate of $0 \cdot 11 \%$. Enhanced vector design enabling inserts to be cloned in all three reading frames with respect to $p h o A$ and optimization of mycobacterial genomic DNA digestions reportedly improved the yield of export-competent inserts to $1.5 \%$ of transformants; a complete analysis of these inserts has still to be presented (Mdluli et al., 1995).

Compared to $p h o A$ gene fusions, the spectrum of signal sequence genes identified with $\beta$-lactamase fusions may be different because selection is based on antibiotic resistance with the latter versus a colour reaction with the former (Smith et al., 1987). The advantages of $\beta$ lactamase fusions in contrast to PhoA fusions as membrane protein topology probes have been reviewed (Broome-Smith et al., 1990). Particularly notable for the purposes of selection for export-competent sequences is the fact that $\beta$-lactamase fusions allow direct selection whereas PhoA fusions require screening of all colonies. PhoA fusions also have the disadvantage that some cytoplasmic fusions display weak enzymic activity, essentially giving false positives (Broome-Smith et al., 1990). In our protocol we potentially selected against fusions that were poorly translocated by direct selection of all transformants at high ampicillin levels. Since precursor forms of $\beta$-lactamase have reduced activity (Roggenkamp et al., 1985; Perez-Martinez et al., 1992), we may have selected for fusions that were processed efficiently by the $E$. coli signal peptidase to generate mature, soluble proteins (Fig. 4). Moreover, by using conditions for inducing the strong Tac promoter, we probably selected against the recovery of $\beta$-lactamase fusions with multiple membrane-spanning, polytopic membrane proteins, which are toxic when overexpressed in E. coli. These considerations probably account for the exclusive identification of $M$. tuberculosis gene fragments encoding typical $\mathrm{N}$-terminal signal sequences in our screen. Interestingly, none of the reported $M$. tuberculosis signal-sequence-encoding genes isolated by phoA gene fusions (Lim et al., 1995; Mdluli et al., 1995; Jackson et al., 1997) appears to match those identified by $\beta$-lactamase gene fusions described here.

With the total sequencing of the M. tuberculosis genome virtually complete (Williams, 1998), the utility of both $\beta$ lactamase and $p h o A$ gene fusions lies not so much in identifying mycobacterial signal-sequence-encoding genes per se, but rather in testing the export competence of putative signal sequences in various bacterial hosts to probe for similarities between mycobacterial, Gramnegative and Gram-positive export pathways. The preliminary characterizations of export-competent $\beta$ lactamase and $p h o A$ gene fusions reported here and elsewhere (Lim et al., 1995; Mdluli et al., 1995; Jackson et al., 1997) are first attempts at throwing some light on this important question. In view of the strong likelihood that exported proteins play a key role in mycobacterial virulence and in potentially eliciting a protective host immune response (Lee \& Horwitz, 1995; Orme et al., 1993; Andersen, 1994; Horwitz et al., 1995), an understanding of the structure, function and regulation of the M. tuberculosis protein export machinery may prove decisive in the design of novel preventive and therapeutic strategies for tuberculosis.

\section{ACKNOWLEDGEMENTS}

This work was supported by funds provided under the Glaxo Wellcome Action TB initiative and by the University of Cape Town. We thank Jan Maarten van Dijl for the vector pGB14 and John T. Belisle for the M. tuberculosis H37Rv genomic DNA. We are indebted to Di James for the automated DNA sequencing.

\section{REFERENCES}

Andersen, P. (1994). Effective vaccination of mice against Mycobacterium tuberculosis infection with a soluble mixture of secreted mycobacterial proteins. Infect Immun 62, 2536-2544.

Belisle, J. T., Vissa, V. D., Sievert, T., Takayama, K., Brennan, P. J. \& Besra, G. S. (1997). Role of the major antigen of Mycobacterium tuberculosis in cell wall biogenesis. Science 276, 1420-1422.

Bolhuis, A., Sorokin, A., Azevedo, V., Ehrlich, S. D., Braun, P. G., de Jong, A., Venema, G., Bron, S. \& van Dijl, J. M. (1996). Bacillus subtilis can modulate its capacity and specificity for protein secretion through temporally controlled expression of the sipS gene for signal peptidase I. Mol Microbiol 22, 605-618.

Brennan, P. J. \& Draper, P. (1994). Ultrastructure of $\mathrm{Myco}$ bacterium tuberculosis. In Tuberculosis: Pathogenesis, Protection, and Control, pp. 271-284. Washington, DC: American Society for Microbiology.

Broome-Smith, J. K. \& Spratt, B. G. (1986). A vector for the construction of translational fusions to TEM $\beta$-lactamase and the analysis of protein export signals and membrane protein topology. Gene 49, 341-349.

Broome-Smith, J. K., Tadayyon, M. \& Zhang, Y. (1990). $\beta$ Lactamase as a probe of membrane protein assembly and protein export. Mol Microbiol 4, 1637-1644.

Content, J., de la Cavellerie, A., de Wit, L., Vincent-Levy-Frébault, V., Ooms, J. \& de Bruyn, J. (1991). The genes coding for the antigen 85 complexes of Mycobacterium tuberculosis and Mycobacterium bovis BCG are members of a gene family: cloning, sequence determination, and genomic organization of the gene coding for antigen $85-\mathrm{C}$ of $M$. tuberculosis. Infect Immun 59, 3205-3212.

Cywes, C., Hoppe, H. C., Daffé, M. \& Ehlers, M. R. W. (1997). Nonopsonic binding of Mycobacterium tuberculosis to complement receptor type 3 is mediated by capsular polysaccharides and is strain dependent. Infect Immun 65, 4258-4266.

Da Silva Tatley, F. M. \& Steyn, L. M. (1993). Characterization of a replicon of the moderately promiscuous plasmid, pGSH5000, with features of both the mini-replicon of pCU1 and the ori-2 of F. Mol Microbiol 7, 805-823.

Das Gupta, S. K., Bashyam, M. D. \& Tyagi, A. K. (1993). Cloning and assessment of mycobacterial promoters by using a plasmid shuttle vector. J Bacteriol 175, 5186-5192.

Dobos, K. M., Khoo, K.-H., Swiderek, K. M., Brennan, P. J. \& Belisle, J. T. (1996). Definition of the full extent of glycosylation of 
the 45-kilodalton glycoprotein of Mycobacterium tuberculosis. J Bacteriol 178, 2498-2506.

Dreyfus, G., Williams, A. W., Kawagishi, I. \& MacNab, R. M. (1993). Genetic and biochemical analysis of Salmonella typhimurium FliI, a flagellar protein related to the catalytic subunit of the $\mathrm{F}_{0} \mathrm{~F}_{1}$ ATPase and to virulence proteins of mammalian and plant pathogens. J Bacteriol 175, 3131-3138.

Fenton, M. J. \& Vermeulen, M. W. (1996). Immunopathology of tuberculosis: roles of macrophages and monocytes. Infect Immun 64, 683-690.

Herrmann, J. L., O'Gaora, P., Gallagher, A., Thole, J. E. R. \& Young, D. B. (1996). Bacterial glycoproteins: a link between glycosylation and proteolytic cleavage of a $19 \mathrm{kDa}$ antigen from Mycobacterium tuberculosis. EMBO J 15, 3547-3554.

Hewinson, R. G. \& Russell, W. P. (1993). Processing and secretion by Escherichia coli of a recombinant form of the immunogenic protein MPB70 of Mycobacterium bovis. J Gen Microbiol 139, 1253-1259.

Hewinson, R. G., Harris, D. P., Whelan, A. \& Russell, W. P. (1996a). Secretion of the mycobacterial 19-kilodalton protein by Escherichia coli, a novel method for the purification of recombinant mycobacterial antigens. Clin Diagn Lab Immunol 3, 23-29.

Hewinson, R. G., Michell, S. L., Russell, W. P., McAdam, R. A. \& Jacobs, W. R., Jr (1996b). Molecular characterization of MPT83: a seroreactive antigen of Mycobacterium tuberculosis with homology to MPT70. Scand J Immunol 43, 490-499.

Hoppe, H. C., de Wet, B. J. M., Cywes, C., Daffé, M. \& Ehlers, M. R. W. (1997). Identification of phosphatidylinositol mannoside as a mycobacterial adhesin mediating both direct and opsonic binding to nonphagocytic mammalian cells. Infect Immun 65, 3896-3905.

Horwitz, M. A., Lee, B.-W. E., Dillon, B. J. \& Harth, G. (1995). Protective immunity against tuberculosis induced by vaccination with major extracellular proteins of Mycobacterium tuberculosis. Proc Natl Acad Sci USA 92, 1530-1534.

Izard, J. W. \& Kendall, D. A. (1994). Signal peptides: exquisitely designed transport promoters. Mol Microbiol 13, 765-773.

Jackson, M., Portnoi, D., Catheline, D., Dumail, L., Rauzier, J., Legrand, P. \& Gicquel, B. (1997). Mycobacterium tuberculosis Des protein: an immunodominant target for the humoral response of tuberculous patients. Infect Immun 65, 2883-2889.

Kuo, C.-C., Takahashi, N., Swanson, A. F., Ozeki, Y. \& Hakomori, S.-I. (1996). An N-linked high-mannose type oligosaccharide, expressed at the major outer membrane protein of Chlamydia trachomatis, mediates attachment and infectivity of the microorganism to HeLa cells. J Clin Invest 98, 2813-2818.

Lee, B.-Y. \& Horwitz, M. A (1995). Identification of macrophage and stress-induced proteins of Mycobacterium tuberculosis. $J$ Clin Invest 96, 245-249.

Lim, E. M., Rauzier, J., Timm, J., Torrca, G., Murray, A., Gicquel, B. \& Portnoi, D. (1995). Identification of Mycobacterium tuberculosis DNA sequences encoding exported proteins by using $p h o A$ gene fusions. J Bacteriol 177, 59-65.

Liu, J., Barry, C. E., III, Besra, G. S. \& Nikaido, H. (1996). Mycolic acid structure determines the fluidity of the mycobacterial cell wall. J Biol Chem 271, 29545-29551.

Mdluli, K. E., Treit, J. D., Kerr, V. J. \& Nano, F. E. (1995). New vectors for the in vitro generation of alkaline phosphatase fusions to proteins encoded by G + C-rich DNA. Gene 155, 133-134.
Orme, I. M., Andersen, P. \& Boom, W. H. (1993). T cell response to Mycobacterium tuberculosis. J Infect Dis 167, 1481-1497.

Paradkar, A. S., Aidoo, K. A., Wong, A. \& Jensen, S. E. (1996). Molecular analysis of a $\beta$-lactam resistance gene encoded within the cephamycin gene cluster of Streptomyces clavuligerus. J Bacteriol 178, 6266-6274.

Perez-Martinez, G., Kok, J., Venema, G., van Dijl, J. M., Smith, H. \& Bron, S. (1992). Protein export elements from Lactococcus lactis. Mol Gen Genet 234, 401-411.

Prinz, W. A. \& Beckwith, J. (1994). Gene fusion analysis of membrane protein topology: a direct comparison of alkaline phosphatase and $\beta$-lactamase fusions. J Bacteriol 176, 6410-6413.

Pugsley, A. P. (1993). The complete general secretory pathway in Gram-negative bacteria. Microbiol Rev 57, 50-108.

Reeves, P. J., Douglas, P. \& Salmond, G. P. C. (1994). Betalactamase topology probe analysis of the OutO NMePhe peptidase, and six other Out protein components of the Erwinia carotovora general secretion pathway apparatus. Mol Microbiol 12, 445-457.

Roggenkamp, R., Dargatz, H. \& Hollenberg, C. (1985). Precursor of $\beta$-lactamase is enzymatically inactive. J Biol Chem 260, 1508-1512.

Salmond, G. P. C. \& Reeves, P. J. (1993). Membrane traffic wardens and protein secretion in Gram-negative bacteria. Trends Biochem Sci 18, 7-12.

Sambrook, J., Fritsch, E. F. \& Maniatis, T. (1989). Molecular Cloning: a Laboratory Manual, 2nd edn. Cold Spring Harbor, NY: Cold Spring Harbor Laboratory.

Silhavy, T. J. (1997). Death by lethal injection. Science 278, 1085-1086.

Smith, H., Bron, S., van Ee, J. \& Venema, G. (1987). Construction and use of signal sequence selection vectors in Escherichia coli and Bacillus subtilis. J Bacteriol 169, 3321-3328.

Sonnenberg, M. G. \& Belisle, J. T. (1997). Definition of Mycobacterium tuberculosis culture filtrate proteins by two-dimensional polyacrylamide gel electrophoresis, $\mathrm{N}$-terminal a mino acid sequencing, and electrospray mass spectrometry. Infect Immun 65, 4515-4524.

Timm, J., Perilli, M. G., Duez, C. \& nine other authors (1994). Transcription and expression analysis, using lac $Z$ and $p$ bo $A$ gene fusions, of Mycobacterium fortuitum $\beta$-lactamase genes cloned from a natural isolate and a high-level $\beta$-lactamase producer. $\mathrm{Mol}$ Microbiol 12, 491-504.

Vosloo, W., Tippoo, P., Hughes, J. E., Harriman, N., Emms, M., Beatty, D. W., Zappe, H. \& Steyn, L. M. (1997). Characterisation of a lipoprotein in Mycobacterium bovis (BCG) with sequence similarity to the secreted protein MPB70. Gene 188, 123-128.

Wiker, H. G., Harboe, M. \& Nagai, S. (1991). A localization index for distinction between extracellular and intracellular antigens of Mycobacterium tuberculosis. J Gen Microbiol 137, 875-884.

Williams, N. (1998). Genome of TB culprit deciphered. Science $279,25$.

Young, D. B., Kaufmann, S. H. E., Hermans, P. W. M. \& Thole, J. E. R. (1992). Mycobacterial protein antigens: a compilation. Mol Microbiol 6, 133-145.

Received 12 August 1997; revised 2 February 1998; accepted 17 February 1998. 